\title{
Reducing Nursing Home Use Through Consumer-Directed Personal Care Services
}

Number 31, April 2008

POLICY PERSPECTIVE

PAST RESEARCH HAS

SHOWN THAT THE CASH AND

COUNSELING PROGRAM

INCREASES MEDICAID

BENEFICIARIES' ACCESS TO AND

SATISFACTION WITH CARE AND

ALSO REDUCES THE STRAIN

REPORTED BY INFORMAL

CAREGIVERS. THIS NEW STUDY

SHOWS THAT THE PROGRAM

REDUCED NURSING FACILITY

USE AND SOME LONG-TERM

CARE COSTS; HOWEVER THE

PROGRAM DID NOT DECREASE

PERSONAL CARE SERVICE

COSTS OR OVERALL MEDICAID

EXPENDITURES MOST LIKELY

DUE TO INCREASED ACCESS TO

CARE. NONETHELESS, POLICY-

MAKERS WISHING TO IMPROVE

BENEFICIARIES' QUALITY OF LIFE

MIGHT CONSIDER ADOPTING

THE PROGRAM, AS IT HELPS

ENSURE THAT BENEFICIARIES

RECEIVE AUTHORIZED SERVICES

WHILE ENABLING THEM TO

REMAIN IN THE COMMUNITY.

\section{Research Highlight}

\section{Background}

The goal of the Cash and Counseling program is to improve the lives of participants and their family caregivers. To accomplish this, the program provides individuals qualifying for Medicaid personal care services with a monthly allowance to hire workers or purchase necessary disability-related goods and services, rather than rely on services supplied and directed by an agency. Prior research on the Cash and Counseling program has shown numerous benefits in terms of increasing beneficiaries' access to and satisfaction with care, and reducing the strain of their caregivers. By providing beneficiaries with the services they need to live at home and by reducing caregiver burden, the program could delay admission to nursing facilities and reduce Medicaid costs for long-term care. However, past studies on the program's effects on nursing home use and on Medicaid costs have only looked at short follow-up periods.

In their study, "Reducing Nursing Home Use Through Consumer-Directed Personal Care Services,"1 Stacy Dale, M.P.A. and Randall Brown, Ph.D., of Mathematica Policy Research sought to determine the effects of the Cash and Counseling program in Arkansas on nursing facility use and total Medicaid costs over a three-year period. To do this, the researchers analyzed the Medicaid claims data of the 2,008 enrollees in the Cash and Counseling demonstration. Upon enrolling, individuals were randomly assigned to one of two groups. One group (the treatment group) participated in the Cash and Counseling program, which meant they could manage a monthly monetary allowance and hire their own workers. The other group served as a control group. Individuals in this group were eligible to receive standard Medicaid personal care services from Medicaid-approved agencies. Outcomes that were examined by the researchers included nursing facility use, nursing facility expenditures, other long-term care expenditures, personal care service expenditures and total Medicaid expenditures.

\section{Key Findings}

- The Cash and Counseling program reduced nursing facility use. By the end of the third post-enrollment year, 15.5 percent of the treatment group never had a Medicaid nursing facility stay, whereas 18.8 percent of the control group had. Thus, Cash and Counseling reduced nursing facility use by 3.3 percentage points (that is, by 18\%). Similarly, only 11.5 percent of the treatment group spent more than 90 days in a nursing facility over the 3 -year post-enrollment period, compared with 14.4 percent of the control group.

- With respect to costs, those participating in the Cash and Counseling program had lower nursing home and other long-term care expenditures but higher personal care service costs. Cumulatively, over the three-year study period, long-term care expenditures (excluding personal care services) per person in the treatment group

1 Dale SB and Brown R. "Reducing Nursing Home Use Through Consumer-Directed Personal Care Services.” Medical Care, 44(8): 760-767, 2006. http://werwe. Ferw-medicalcare.com/pt/re/medcare/abstract.00005650-200608000-00009.btm;jsessionid $=$ Hr8GqCFSNtH3VLjGwTHOJ6JmWsybmmCcOjG9ngXweshdtRkyrbRKn!1675702673!181195628!8091!-1 
were about $\$ 1,900$ less than the corresponding expenditures for the control group. However, Medicaid spent almost \$5,500 more on personal care services per person for treatment group members than for those in the control group. The authors cite increased access to care as the cause for the increased spending, because many control group members received none of the authorized personal care, and control group recipients received only about two-thirds of the authorized amounts.

Medicaid Expenditures in Arkansas's Cash and Counseling Program by whether Personal Care Services (PCS) were Used before Enrollment

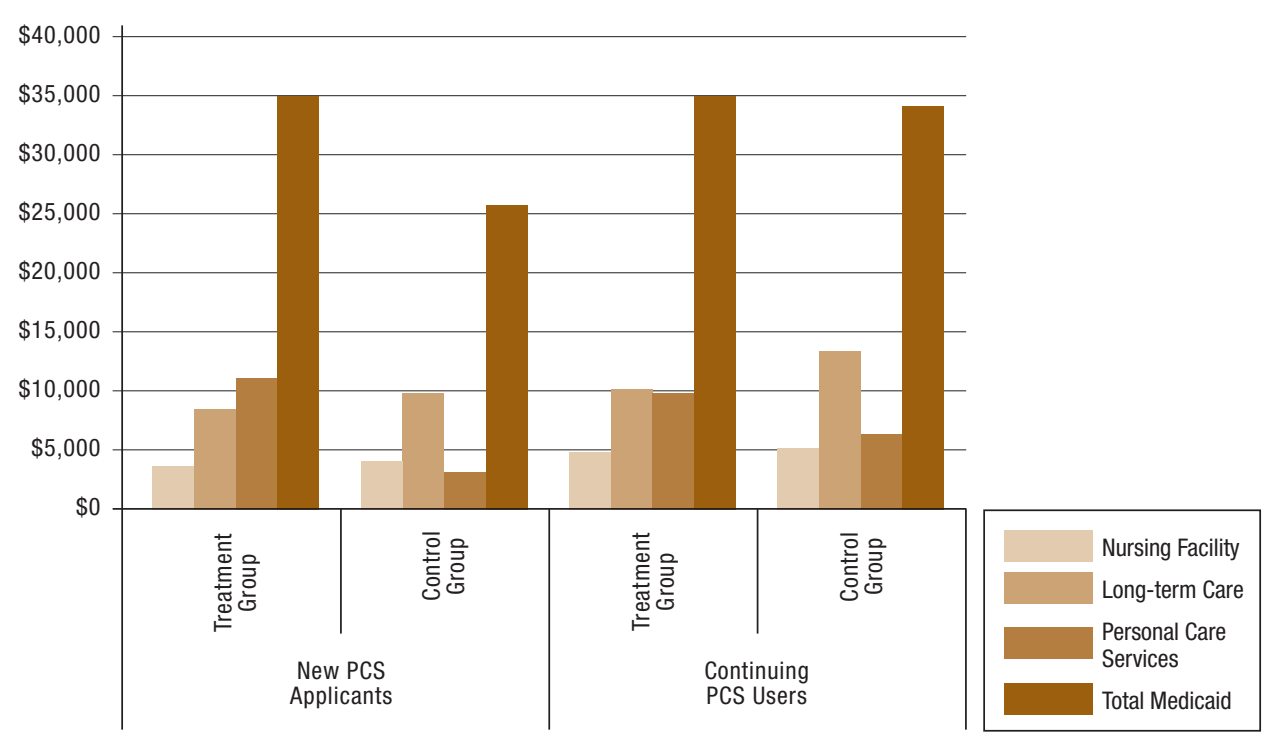

- Over the three years of the study period, the difference in total Medicaid costs of the treatment and control groups decreased until there was no statistically significant difference between the groups. During the first year, total Medicaid costs of the treatment group were about $\$ 1,500$ greater than those of the control group. This gap, however, decreased over time with the difference between the two groups falling to about $\$ 900$ per person during year two and to about $\$ 600$ (and statistically insignificant) during year three. When looking at those who were already receiving Medicaid Personal Care Services at the time they enrolled, the increases in personal care costs were fully offset by the decreases in long-term care costs. This was not true for those who were not previously receiving Medicaid Personal Care Services; for this subgroup, the treatment-control difference in personal care expenditures was very large because only about one-fourth of control group members received any personal care services.

-Deanna Lewis

Deanna Lerwis is a Rutgers University/Robert Wood Johnson Foundation Policy Analyst. 